\title{
THE GREAT TANGENT GALVANOMETER OF THE CORNELL UNIVERSITY.
}

\author{
BY PROFESSOR WM. A. ANTHONY.
}

THE "mammoth tangent galvanometer" which was described in the Electrician and Electrical Engineer, of October, 1885, has now been in use for nearly a year, and it may be of interest to the Institute to hear a brief account of its working. It will be remembered that the instrument was constructed primarily for the direct measurement of large currents, and its large dimensions were necessary to adapt it to that purpose. At the same time it is possible to measure by means of it, currents as small as 1-100th ampére. The instrument is fully described in the Electrician and Electrical Engineer, but a description is given here in order that the various uses to which it has been put may be better understood. The needle is made of a number of thin wires, is hung in a copper block, and is very nearly dead-beat. The apparatus for observing deflections, gives these accurately to 20 seconds. The coils for heavy currents each consist of a single turn of copper rod $1.9 \mathrm{~cm}$. diameter. There are four coils, two of them $200 \mathrm{~cm}$. and two $160 \mathrm{~cm}$. diameter. These are placed parallel to each other, the two coils of a pair being at a distance apart equal to their radii. As the coils can be used in series, in pairs, singly, or differentially, it will be seen that the galvanometer may be equally sensitive to widely different currents. In fact, currents of any value from 4 to 250 ampéres, can be measured by deflections of the needle never less than 25 nor more than 60 degrees. Four coils of 18 turns each of small wire, serve to measure smaller currents. The instrurnent has been used for measuring currents of dynamos under test, for measuring currents, for standardizing other instruments, and for a great variety of experimental work.

Its indications have been compared with those of the copper voltameter, with generally a very close agreement. The disagreements that have been observed, have been traced to irregularity in the action of the voltameter. It has also been compared with a calorimeter with very satisfactory results. All the observations that have been made with it, go to show that its indications may be inplicitly relied on. In fact, those who have used it, have come 
to feel the same confidence in the results obtained, as when weighing a body on a good balance. In the use of the instrument, readings can be taken very rapidly, ten minutes sufficing for twenty readings which are ordinarily taken as a set in measuring currents, and the computation of results is extremely simple. There are no temperature corrections except where the highest degree of refinement is aimed at. The only correction that need to be considered in any ordinary case, is that due to variations in the horizontal intensity of the earth's magnetism, and the instrument contains within itself the means of determining the horizontal intensity at any time.

The advantages of the galvanometer over other methods of measuring large currents, will appear by considering the sources of error or uncertainty involved. Currents may be measured by shunting a smaller tangent galvanometer. Here the errors depending on the instrument itself are the same as for the larger instrument, but larger in proportion, since the dimensions of the smaller instrument cannot be measured with the same percentage of accuracy as of the larger. But in addition to these, there is the uncertainty in regard to the shunt ratio, which depends upon temperatures very difficult to determine accurately. With copper conductors, a change in the ratio of one per cent. would result from a difference of temperature of a very few degrees.

Theoretically, the best way to measure currents would be by reference to their own mutual action. That is, by means of some form of the electro-dynamometer. But any such instrument, when constructed for measuring large currents, involves large sources of error. The instrument must be of large dimensions, otherwise the cross section of the conductors will be large in proportion to the distances between them, a condition which makes it impossible to determine the constant of the instrument with certainty. The forces to be measured are very small, and any arrangement for carrying the current to and from the movable coil, must seriously interfere with its freedom of motion, and so impair the sensitiveness of the instrument. The writer of this paper had planned to construct a dynamometer in which a movable coil should be suspended from the arm of a balance, and the force exerted between it and the fixed coil, weighed, but no method could be devised for reaching the suspended coil with a current of 20 amperes even, without a loss of eensitiveness that was fatal.

Currents may be measured by determining the deposit of cop- 
per or silver. In theory this is very simple, but in practice, constant results can be obtained only by observing many precautions, and even with the greatest care, results will sometimes differ by one or two per cent. from the truth, without apparent cause. Moreover, these voltameter methods are not generally available, as they require too much time, and give only a time integral of the current, and not its value at any given instant. They are only of value for the calibration of instruments whose constants cannot be determined from their own dimensions, such as the various forms of ammeters, including the so-called "Vienna method." The indications of all such instruments are uncertain, unless they are frequently calibrated. If permanent magnets are used to produce a magnetic field, they are liable to a continuous change, and they always change in strength with change of temperature. If any of the forms of mirror galvanometer are used, as in the "Vienna method," the slightest change in the position of the needle with reference to the small coil, such as might occur from a stretching of the fibre, will change the constant.

To sum up: The tangent galvanometer is a very sensitive instrument, and its constant depends only upon its dimensions and the horizontal intensity of the earth's magnetism. Temperature affects the constant only as it affects the dimensions of the instrument. For the shunted galvanometer the constant depends upon the same elements, with the addition of a very uncertain shunt ratio.

The voltameter is usually inadmissable for direct measurements of currents, and the method requires extreme care to avoid errors in determining the deposit, which errors may arise from some of the solution being occluded in the deposited metal, or from loss of the metal while washing, or from other causes, difficult sometimes to assign. Moreover, this method is not an absolute method. Electrodynamometers, when constructed for use with large currents, lack sensitiveness.

Of course, the large tangent galvanometer is not a portable instrument. Few instruments of precision for absolute measurements are. It must be mounted in a place free from local magnetic disturbances. But it is the conviction of the writer, after extended experience, that, for purposes of accurate testing, or for standardizing other instruments, there is no other method for measuring currents, so reliable, so accurate, and so expeditious.

Physical Laboratory of the Cornell

UNIVERSITY, May 15th, 1886. 
Thy: President: The measurement of heavy electric currents, such as are used for lighting and power, is almost a new subject, and perhaps the first work that has been done in that line approximating strict accuracy is that which has been accomplished by means of Prof. Anthony's galvanometer, which he has spoken of in this paper. If there are any present who wish to make any remarks they have an opportunity.

Mr. LaIN : As I had the privilege of being in attendance at Cornell the year in which this instrument was built, though it was also my misfortune to be obliged to leave the University, since I graduated last June, just before the instrument was in successful working,--in Prof. Anthony's absence I may be able to say something about it. A description of the instrument has, perhaps, been read by most of those present, but the way in which Prof. Anthony removes the errors of construction and errors liable to arise from surrounding influences certainly deserves some mention. In the first place, he received a large appropriation for the instrument and its appurtenances, and a house was especially built for this one instrument, a small frame house, in the construction of which not a particle of magnetic metal was allowed. The nails used were all of copper, the hinges were of brass. A copper stove was built especially for it and a copper stove pipe, and the gas pipes leading to it were of lead instead of iron, and then, as will be seen by the description in the Electrician and Electrical Engineer, the mechanical construction of the instrument is such that the errors of construction are removed almost entirely. Then Prof. Anthony speaks of the errors in the use of the copper voltameter. I chose that subject for a thesis last June, and was very much surprised at the obstacles I met in working it. I started out with something like twenty-four cells in series, and whenever one cell was stopped of course they would all be stopped, and the current started on one of them would also pass through each one of the others; and I found by taking the greatest possible pains that the discrepancies in the increase of the deposits on the negative plates were much larger than I anticipated. These arise from a variety of causes. In the first place, there is the addition of the salt of the liquid-the sulphate of copper-to the plate, which is accidental, and therefore irregular, that is, it appears that the liquid is built in with the deposit. Well, whatever liquid is built in in that way adds to the 
weight, and therefore makes an error in the computation. First, I thought it sufficient to simply allow the plates to be nominally dried before weighing them, but, after experimenting for a long while, I found that I obtained quite different results, if the plates were desiccated before weighing; so that the conclusions I arrived at in my thesis were that unless there was some arrangementsome acidity of solution, such that the amount of the metal removed by the chemical corrosion was exactly equal to the added weight due to this imprisoned salt-unless this shonld be arrived at, the voltameter would show results that were not accurate.

Mr. Mailloyx: I would like to add in confirmation of the gentleman's experience, that for the last year I have been devoting my time almost entirely to working copper, and one of the first things I found was that there was almost an impossibility of making a relation between the amount of copper deposited and the amount of current passing. The books state that one ampere of current passed through for 386.4 hours will deposit a pound of copper, but I confess I have never made practice come to theory or agree with it. I was working for industrial purposes, one of which was electrotyping, and I have come to the conclusion that a great many of the determinations that have been made by means of the voltameter, using copper, and even silver mast have been erroneous, and as the gentleman says there are some obscure causes involved, one of which he has brought to notice and another one which I think has not been mentioned before, and which is the occlusion of hydrogen by the metal itself. I had found that out practically by experiments. If a solution is not of the right constitution, instead of depositing copper you are depositing copper and hydrogen, and when you come to weigh the copper you weigh only the copper; you have no means of estimating the amount of hydrogen that is occluded,there. As a matter of fact, you would never know there was hydrogen there. It took me a long time to surmise that hydrogen was there. It is said you get evidence of hydrogen when the copper is granulous-black. I have found hydrogen when the copper was perfectly regular, perfectly good and clear. I have deposited two pieces of copper and at the end of a week one would be perfectly rotten and the other as hard and tough as hammered copper, and that, I think, is one of the sources of error which make the copper voltameter utterly unreliable. I think that some form of tangent galvanometer, which gives the thing an absolute 
measurement taking the earth's component of magnetism as the starting point, is probably the most satisfactory thing you can get.

The President : I have observed for a long time that the confidence of experimenters in the results obtained with the voltameters were apt to be in the inverse ratio to the amount of their experience with it. Mr. Edward Weston, who I am very sorry not to see here to-day, has done a great deal of practical work in electrolysis and electroplating for many years, but has never been able to get any results which he had any particular confidence in, and his confidence has diminished the longer he has gone on. I have talked with him about it a gond many times. I very much regret he is not here to give us the benefit of his experience, but it accords very closely with that of the two gentlemen who have last spoken, and of others that I might mention, and I think we might consider that it is pretty well established that it is not safe to place any very great confidence in the results obtained by the voltameter unless checked by independent sources.

Prof. Young: I was going to say there was one peculiar experience of Prof. Anthony which he does not speak of in this paper, namely, that the stiffness of the suspended wire is all the time increasing and the time of the vibration of the needle is increasing. I wonder whether others have come upon that same thing. I have found that the springs of our clocks at our observatory at Princeton are growing stiffer. Our mean time clock has certainly in that way increased its rate as much as some few seconds a day, in the last few years, I suppose from the increased hardening of the springs. Prof. Anthony finds it necessary in his galvanometer to check this co-efficient of torsion.

The Presiden'r: That is a very interesting observation of Prof. Anthony's and should be borne in mind.

The Secretary: It has occurred to me that as one of the blessings which we were to derive from incandescent electric lighting was the reliability of the electric meter, which I believe is based on this principle of depositing copper, it would be quite interesting to know if the error alluded to would be in favor of the consumer or the producer of the electric light.

Mr. Lockwood: I would say, Mr. President, that is a question that will always answer itself, the same as the gas meter does.

The President : I believe that the actual method adopted and practised is a zinc voltameter. It has been stated in accounts 
which have been published of the central station lighting systems of this country in which this method of measurement is used, that the results are accurate within one per cent. I think there can hardly be any doubt that this is somewhat of an exaggeration, because I fancy it would be difficult to get that result in a laboratory every trial with all the time required to make the measurements. But it is very probable, I should think, that the results might be depended upon within four or five per cent. I should be very glad if any one present could give any information on that point. It is a matter of a good deal of practical interest. If there are no further remarks to be made on this paper, I would say that a little collation has been provided, and we will now take a recess of an hour to discuss that, after which we will listen to a paper by Mr. Thomas D. Lockwood, of the American Bell Telephone Company, on "Some Recent Advances in Telephony."

A recess was then taken.

The afternoon session convened at 2.15 o'clock, when Mr. Lockwood read his paper. 